\title{
NCAA Website Coverage: An Analysis of Similar Sport Team Gender Coverage on Athletic Department's Home Web Pages
}

\author{
Coyte Cooper
}

West Virginia University

\begin{abstract}
Since the implementation of Title IX, women have received increasing educational participation opportunities within the intercollegiate athletic setting (Student-athlete, 2006). While female athletic participation rates are at an all-time high in the National Collegiate Athletic Association (NCAA Sports, 2006), some additional concerns arise when focusing on promotional media coverage provided to women on athletic departments' home Web pages. The purpose of the current study was to investigate the coverage (advertisement, article, multimedia, and photograph) provided to similar sport teams on intercollegiate athletic websites during an academic year. Despite the fact that women's softball teams consistently received less coverage than men's baseball teams, the results illustrated that men's and women's similar sport teams receive comparable coverage allocations on intercollegiate athletic department's home Web pages. The implications of the findings are discussed in depth in the paper.
\end{abstract}

During the past 30 years, Title IX has had a lasting impact on participation opportunities offered to females in a myriad of different educational settings (Title IX, 1997). While numerous educational programs have been positively impacted, one setting in particular has witnessed dramatic increases in opportunities available to women: intercollegiate athletics. From 1981 to 2006, the number of sport teams offered to women within the National Collegiate Athletic Association (NCAA) more than doubled from 4,279-8,991 (Student-athlete, 2006). Similarly, when focusing on athlete participation rates from 1995 to 2005, the number of women participating in the NCAA increased by 39,748 athletes (Student-athlete, 2006). In comparison, during the same time frame, men realized the following participation increases at the NCAA level: 1,270 new sport teams and 13,389 additional athletes. Thus, while females do not show equitable participation rates in comparison with proportional university enrollment rates (Huffman, Tuggle, \& Rosengard, 2004), data supports the notion that women are receiving increasing support from the NCAA in the form of enhanced participation opportunities.

While women's participation rates have reached an all-time high within the NCAA (NCAA Sports, 2006), several concerns must be addressed when attempting to ensure that females are provided with an equal opportunity to benefit from

The author is with West Virginia University, School of Physical Education, P.O. Box 6116, Morgantown, WV, 26506-6116. 
college athletics. In addition to the general opportunities and services provided by athletic departments (Title IX, 1997), a modern concern is the media coverage afforded to females in a variety of different outlets. After all, as previous research has demonstrated, when females are not fairly represented in media coverage allocations, they are not provided with an opportunity to promote their product to potential consumers (Coakley, 1998; Cunningham, Sagas, Satore, Amsden, \& Schellhase, 2004). As a result, consumption of and future interest in women's sports can suffer because females are not afforded the opportunity to brand their product to current and potential fan segments (Gladden \& Milne, 1999). The aim of the current study was to build on previous gender issue research related to sport media through the investigation of similar sport team coverage on athletic departments' home Web pages.

\section{Brand Equity}

Brand equity is defined as "a set of assets linked to a brand's name and symbol that adds to (or subtracts from) the value provided by a service or a firm and/or that firm's customer" (Aaker, 1996, p. 15). In past sport management literature, scholars have clearly outlined the importance of brand equity on the success of a business operation (Ross, 2006). From a commercial standpoint, scholars have demonstrated that a strong brand image directly correlates with the following benefits: increased merchandise sales (Gladden \& Milne, 1999), enhanced product image (Gladden, Milne, \& Sutton, 1998), and increased overall value of a product (Keller, 2003). While a few researchers have claimed that consumer interest is dependent upon the brand equity of a particular sport (Cunningham \& Sagas, 2002), other scholars have taken an alternate approach by arguing that promotions and advertising play a critical role in the strengthening of brand image in the minds of consumers (Söderman \& Dolles, 2008).

Similar to the perspective illustrated by Söderman and Dolles (2008), several sport management researchers have also stressed the influence of media coverage on consumer preferences (Duncan, Messner, Williams, \& Jensen, 1994; Gladden et al., 1998; Kane, 1988). As explained by Kane (1988), the media is one of the most influential institutions that shape values and attitudes of individuals residing within any society. When the media decides not to provide women with equitable coverage, they are essentially sending the message that women's sports are not important (Pedersen, 2002). In addition, it is this lack of coverage that sets a precedent for inequitable treatment to be regarded as appropriate and normal (McGregor, 1989; Sagas, Cunningham, Wigley, \& Ashley, 2000).

Several authors have emphasized the negative implications of gender coverage inequalities in the sport media (Kane, 1988; Rintala \& Birrell, 1984). Cunningham et al. (2004) explained that in addition to shaping public perceptions of the value of female sports (Coakley, 1998), inequitable media representation results in females being deprived of necessary exemplars to emulate. As a result, Pedersen (2002) noted, this inequitable social framing can not only impact future participation rates, it can also cause women to lose out on professional and personal skills learned through sport-related activities. Thus, the presence of coverage inequalities can eliminate long-term professional opportunities realized by women who might have participated in sport had they been encouraged to do so. 


\section{Literature Review}

The current examination of athletic department websites builds on an extensive body of literature that has focused on the gender coverage being provided in a variety of different media outlets (Cuneen \& Sidwell, 1998; Duncan \& Sayaovong, 1990; Fink \& Kensicki, 2002; Pedersen, 2002). While the results in previous studies have varied slightly, the interpretation of the data has been clear: women are not equally representated in sport media outlets in comparison with men (Bryant, 1980; Duncan et al., 1994; Kane, 1988). For example, Cuneen and Sidwell (1998) demonstrated that men were 12 times more likely to be featured in Sports Illustrated for Kids than women. Similarly, Fink and Kensicki (2002) found that women received only $10 \%$ of the article and photograph coverage in Sports Illustrated.

Recently, scholars have emphasized the importance of focusing on not-forprofit media outlets with an NCAA affiliation (Cunningham \& Sagas, 2002; Sagas et al., 2000). In addition to potential Title IX and ethical concerns, Cunningham et al. (2004) provided the following reasoning for focusing on the gender coverage within not-for-profit media outlets:

Given the dependence upon consumers and consumer preferences among forprofit media outlets, an alternative approach is to study the representation of men and women in not-for-profit media outlets, such as university newspapers, athletic department Internet Web sites, and/or the NCAA News.

Despite demonstrating that women's teams are underrepresented in comparison with their male counterparts, early studies on not-for-profit media outlets show that women received more favorable coverage allocations within media outlets such as the NCAA News and campus newspapers (Shifflet \& Revelle, 1994; Wann, Schrader, Allison, \& McGeorge, 1998) than they did in for-profit publications. In an early analysis of the NCAA News, Shifflet and Revelle (1994) revealed that women received $29 \%$ of the article coverage and $34 \%$ of the photographic journalism in the publication. Similarly, in a follow-up study of the NCAA News a decade later, Cunningham et al. (2004) reported that women received slightly higher article (42.4\%) and photograph (39.7\%) coverage allocations within the publication than previously.

In addition to the NCAA News, scholars have also focused on the gender coverage within campus newspapers (Wann et al., 1998, Huffman et al., 2004). Similar to the content analyses performed on the NCAA News, the data from the studies on campus newspapers confirmed that women received more favorable coverage allocations in these publications than in for-profit media outlets (Bryant, 1980; Fink \& Kensicki, 2002). For example, Huffman et al. (2004) showed that women received $27.3 \%$ of the coverage provided within the campus newspaper publications. Despite this fact, the authors stressed that women were still underrepresented in comparison with NCAA participation rates and proportional university enrollment ratios.

In recent years, researchers have also provided insight into gender coverage provided by a modern, innovative media outlet: intercollegiate athletic websites (Cunningham \& Sagas, 2002; Sagas, Cunningham, Wigley, \& Ashley, 2004). To investigate gender coverage at these sites, Cunningham and Sagas (2002) compared similar sport team coverage (men's basketball, men's baseball, women's basketball, and women's softball). According to the authors, the men's baseball 
teams received significantly more coverage than the women's softball teams in a variety of the coverage areas examined.

The purpose of the current study was to add to research on the gender coverage provided by sport media. In addition, to follow up on similar sport team results provided by Cunningham \& Sagas (2002), this study was also designed to add depth to the literature by examining the coverage provided to the following similar sport teams: cross-country, golf, soccer, swimming, and tennis. ${ }^{1}$ Similarly, the study also built on previous research by investigating two modern units of measurement featured on intercollegiate athletic home Web pages: advertisements and multimedia content.

Following a review of the related literature on sport media gender coverage, the following hypotheses were created to guide the research:

Hypothesis 1: Men's similar sport teams will receive significantly more coverage than women's similar sport teams within the units of measurement examined during the study.

Hypotheses 2: Men's similar sport teams will receive significantly more prime coverage (i.e., nonscroll, multimedia) than women's similar sport teams within the units of measurement examined during the study.

\section{Methodology}

\section{Targeted Athletic Departments}

The research included websites from 20 different Division I athletic departments representing the following five athletic conferences throughout the United States: the America East Conference, the Atlantic Coast Conference (ACC), the Big Ten Conference (Big 10), the Ivy League Conference, and the Pacific-10 Conference (Pac-10). To achieve a sample representative of the athletic departments at the Division I level, a decision was made to randomly select athletic departments $(N$ $=20$ ) that sponsored the required six female and male similar sport teams (see Table 1). The 12 team requirement was used as a benchmark to ensure that direct team comparisons could be made during the data analyses process. Thus, the sample was representative of the Division I athletic programs featuring each of the sport teams investigated during the study.

\section{Seasonal Sampling}

The current study involved the analysis of similar sport teams during the 2005-06 academic school year. Because the sample included teams representing each sport season, a decision was made to obtain a random one-week sample from each of the sport seasons featured during the academic year: fall, winter, and spring. Thus, the overall constructed three-week sample of the 20 athletic programs created a total of 420 home Web pages for analysis during the study. The data collection process started during the fall sport season and concluded with the spring sport season. 


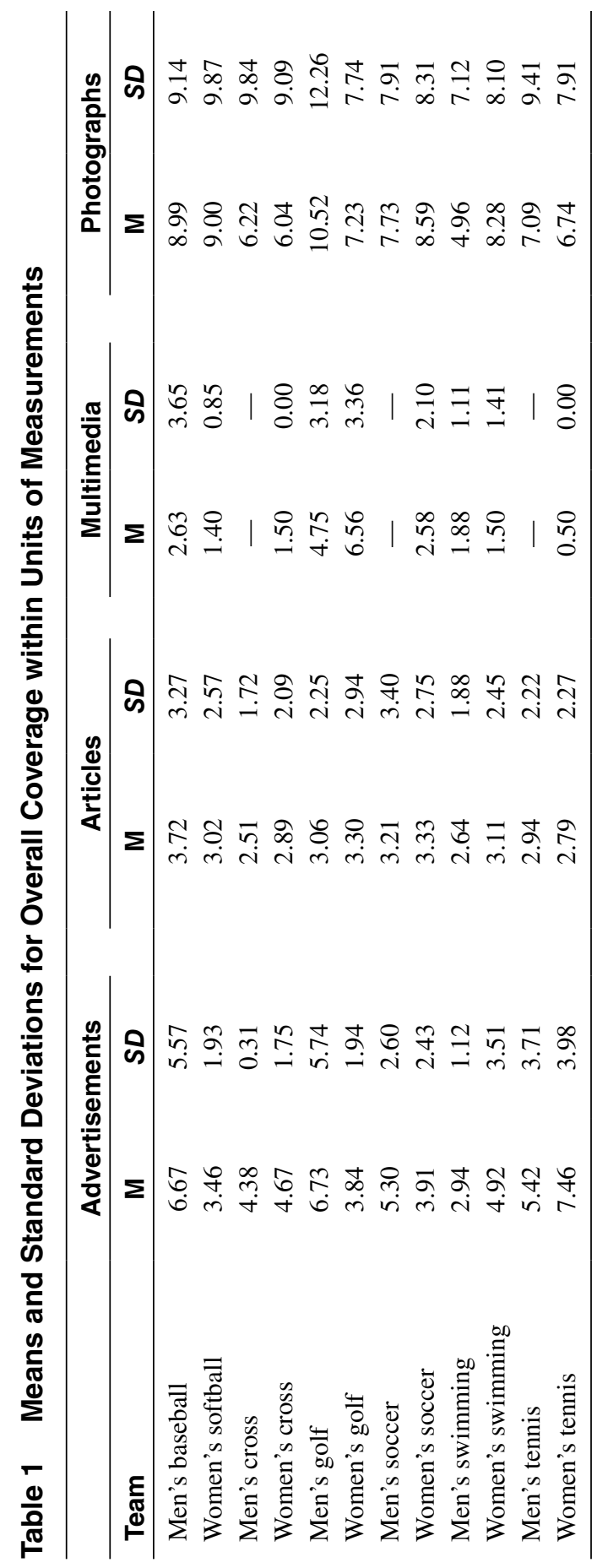




\section{Data Collection}

During the study, the data collection process focused on the identification of the overall and nonscroll coverage featured during the study. The nonscroll measure was featured as the coverage with prime location, and it was defined as the content that appeared directly on the page when accessing each home Web page. With the variations in computer settings, the study maintained reliability by collecting nonscroll data in a consistent manner. For example, the coders used for the study collected data with a standard protocol that included identical computer screen sizes and browser settings. Thus, procedures employed in data collection guaranteed that each team in the study had an equal opportunity to receive "prime" nonscroll coverage.

Within the study, the overall and nonscroll data were gathered in the following four categories of coverage: articles, advertisements, multimedia, and photographs. The advertisement unit of measurement included such things as ticket sales and block advertisement provided directly to each team on the athletic departments' home Web pages. Similarly, the multimedia content included the audio and video content (e.g., video interviews, audio game broadcasts) dedicated to sport teams on the home Web pages. Similar to Malec's (1994) study, the team measure included only coverage provided directly to each team and did not count "combined" or "neither" categories.

To ensure reliability in the research, the study included intercoder testing between the two trained coders involved in the data collection process. Overall, the comparisons between the coders involved the independent analysis of 100 randomly selected websites ( $23.8 \%$ of sample). The percentages of chance agreement were calculated to determine the level of agreement between the two coders. In addition, the Adjusted Scott's Pi was used as a measure to ensure that similar results were not provided by chance alone (Riffe, Lacy, \& Fico, 2005). According to Riffe et al. (2005), the results of the percentages of chance agreement (90.3$97.1 \%$ ) and the Adjusted Scott's Pi (.892 to .962) were both sufficient. Thus, the coders were providing highly similar results within each of the units of measurement examined. Following the intercoder reliability testing, the remaining 320 home web pages were divided evenly between the two coders for independent data collection.

\section{Data Analysis}

The data analysis process involved a series of statistical procedures that were used to test each of the hypotheses. To gain a broad understanding of the data, the means and standard deviations within each unit of measurement were calculated for each of the teams included in the study (see Table 1). In addition, an analysis of variance (ANOVA) was used to identify the differences in the average length of coverage items (i.e., advertisement, article, multimedia, and photograph) provided to the similar sport teams included in the sample. Furthermore, chi square analyses were conducted to determine whether significant coverage differences existed between men's and women's similar sport teams when focusing on the square inch coverage presented during the study. 


\section{Results}

In Hypothesis 1, it was predicted that men's similar sport teams would receive significantly more coverage than women's similar sport teams within the units of measurement examined during the study. Overall, when focusing on the means and standard deviations of the sport teams, the data (at least in part) failed to support the hypothesis. As shown in Table 1, women's sport teams received higher mean coverage values than men's sport teams during 14 of the $24(58.3 \%)$ similar sport team comparisons. Similarly, the investigation of the nonscroll coverage included in the study revealed that women received higher mean coverage values during 10 of the 24 (41.6\%) similar team comparisons (see Table 2). Thus, the data seem to support the notion that women's and men's similar sport teams are, at least in general, receiving comparable coverage.

In addition to overall mean values, the results also identified where statistically significant differences existed in the length of coverage between men's and women's similar sport teams. As illustrated in Table 3, the analysis of variance demonstrated that the advertisements provided to men's baseball $(M=6.67, S D=$ $5.57)$ teams were significantly longer than those provided to women's softball $\left(\mathrm{F}_{1}\right.$, $\left.{ }_{60}=8.33, p<.001\right)$ teams. Similarly, men's baseball teams, in contrast to softball, also had longer articles $\left(\mathrm{F}_{1,324}=1.62, p<.001\right)$ and more multimedia content $\left(\mathrm{F}_{1}\right.$, $\left.{ }_{52}=18.33, p<.001\right)$. In contrast, the data also showed that women's swimming teams received significantly longer advertisements $\left(\mathrm{F}_{1,39}=0.10, p<.001\right)$ and articles $\left(\mathrm{F}_{1,115}=0.59, p<.001\right)$ than men's swimming teams. Additional results are provided in Table 3.

The chi square comparisons also illustrated the statistically significant differences in the overall square inch coverage offered to similar sport teams. The data confirmed that men's baseball teams received significantly more overall square inch coverage than women's softball teams within each of the following units of measurement: advertisements $\left(\chi^{2}=63.18, p<.001\right)$, articles $\left(\chi^{2}=25.09, p<\right.$ $.001)$, multimedia $\left(\chi^{2}=42.20, p<.001\right)$, and photographs $\left(\chi^{2}=3.96, p<.05\right)$. Similarly, when focusing on the remaining data, the results demonstrated that women's soccer $\left(\chi^{2}=44.54, p<.001\right)$ and swimming $\left(\chi^{2}=43.57, p<.001\right)$ received less overall advertisement coverage than their male counterparts. Conversely, results also confirmed that men's golf teams received significantly less multimedia coverage than the women's golf teams $\left(\chi^{2}=31.74, p<.001\right)$

In hypothesis 2 , it was proposed that men's similar sport teams would receive significantly more prime coverage than women's similar sport teams within the units of measurement examined during the study. Analysis of nonscroll coverage demonstrated that only three significant differences existed between the similar sport teams. Similar to the overall coverage allocations, men's baseball teams received significantly longer nonscroll advertisements $\left(\mathrm{F}_{1,37}=38.39, p<.001\right)$ and multimedia content $\left(\mathrm{F}_{1,33}=24.83, p<.001\right)$ than women's softball teams. Men's golf received significantly longer nonscroll advertisements than the women's team (Table 4). The remaining data on prime coverage showed no statistically significant differences between men's and women's similar sport teams.

Chi square analyses further illustrated the differences in the nonscroll coverage being provided to the sport teams during the study. Similar to the overall 


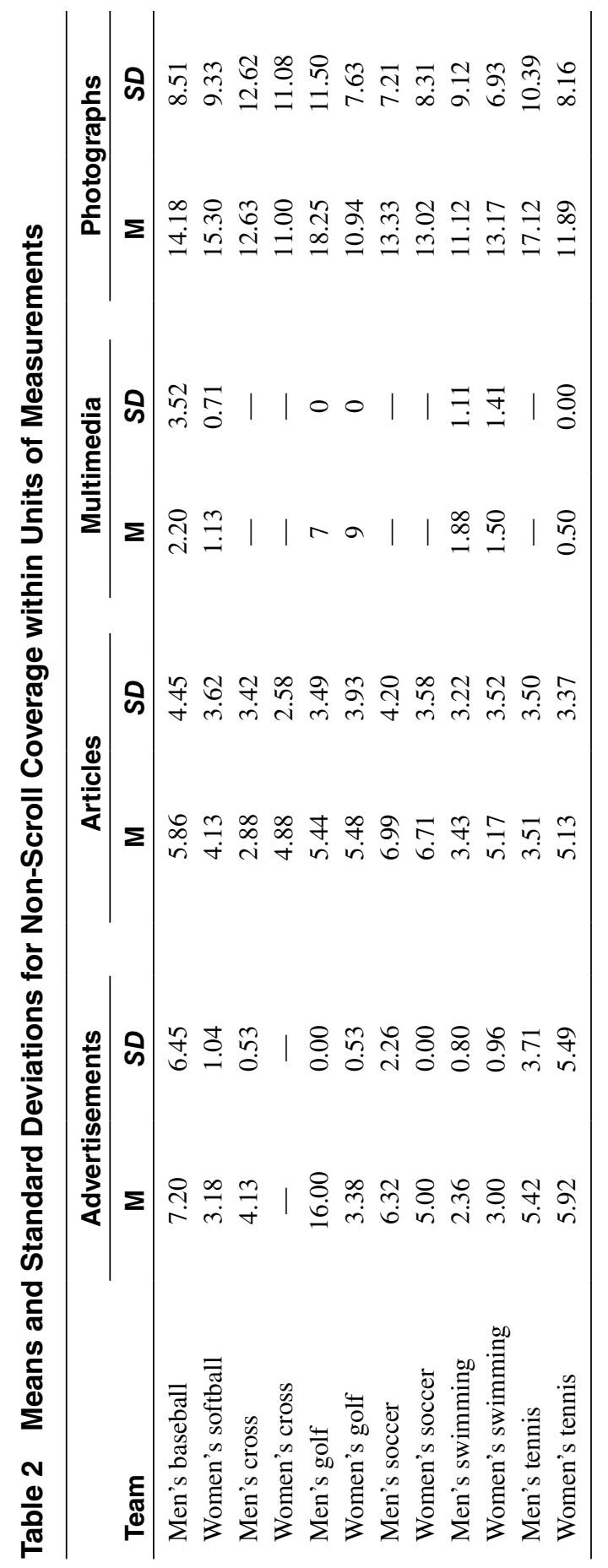




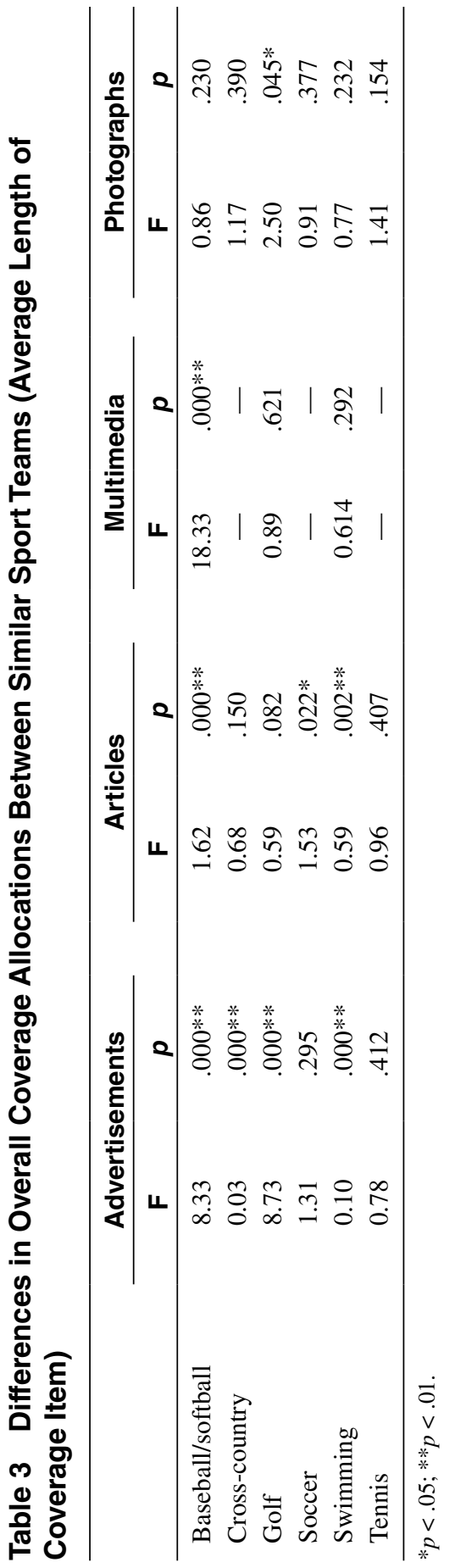




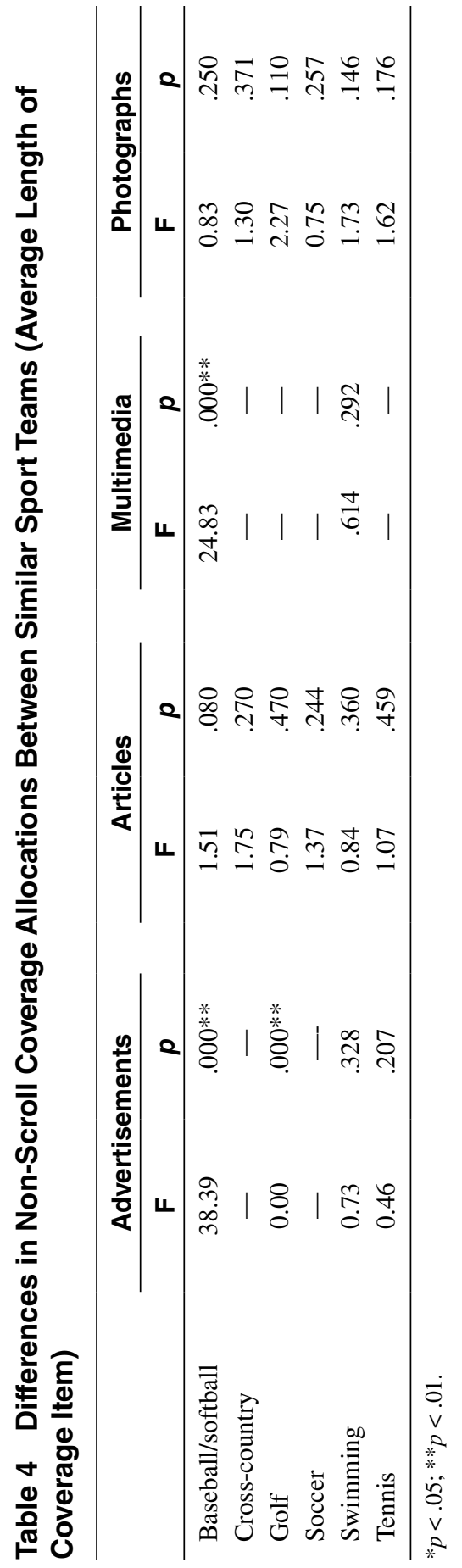


coverage, the data showed that the men's baseball team received significantly more nonscroll advertisement $\left(\chi^{2}=76.69, p<.001\right)$ and multimedia $\left(\chi^{2}=20.14\right.$, $p<.001)$ content than the women's softball team. The results also confirmed that women's soccer team received significantly less nonscroll advertisements than the men's soccer team $\left(\chi^{2}=80.4, p<.001\right)$. Furthermore, the men's golf team received significantly less nonscroll advertisements than the women's golf team $\left(\chi^{2}=\right.$ $40.08, p<.001)$.

\section{Discussion}

\section{Similar Sport Team Gender Allocations}

The purpose of the study was to investigate the gender equity of similar sport team gender coverage on athletic departments' home Web pages. Overall, the data seemed to support the notion that athletic programs have varying agendas or purposes when promoting the various nonrevenue sport teams. Similar to the study performed by Cunningham and Sagas (2002), in which they suggested that baseball enjoyed a higher perceived brand image than softball, results indicated that the greatest differences in coverage allocations occurred between these two sports. In addition to a higher quantity of overall coverage, the findings illustrated that the men's baseball team received more space within prime coverage areas (e.g., nonscroll multimedia).

Despite the differences between men's baseball and women's softball teams, the remaining results demonstrated more favorable coverage allocations for the women's sport teams featured in the study. In fact, outside of a couple of coverage discrepancies between men's and women's soccer, the data show that men's and women's sport teams received comparable allocations. From a broad perspective, this finding is encouraging for one critical reason. In direct comparison with the study performed by Duncan and Sayaovong (1990), the results demonstrate that females are receiving equitable coverage allocations within sports considered as "sex-inappropriate." Furthermore, the allocations are also promising because they far exceed the allocations previously afforded to women in "for-profit" media outlets (Cuneen \& Sidwell, 1998; Fink \& Kensicki, 2002).

From a similar sport team perspective, the findings suggest that athletic programs are, for the most part, making a concerted effort to afford equitable gender coverage to similar sport teams. The results are of the utmost importance because they demonstrate that athletic departments are providing women and men with similar opportunities to brand their product. In addition to building their brand image with consumers (Gladden et al., 1998), the allocations help ensure that women are given an equal opportunity to build interest in their sports in future generations (Cunningham et al., 2004). Such interest may have an indirect domino effect in helping young women gain professional skills that can be learned through sport participation (Pedersen, 2002).

While the results of the study are somewhat promising from a similar sport team perspective, additional gender concerns emerge when focusing on the overall coverage that is provided on intercollegiate athletic websites. The inclusion of football (with upwards of $32 \%$ coverage allocation) during the "arms race era" 
(Kennedy, 2007), reveals a large overall disparity between male and female team coverage. Thus, with football site promotions in the equation, and with increasing coverage going to football during the this period of arms race competition, comparable coverage is still a goal, not a reality. For future compliance with Title IX (Title IX, 1997), researchers will need to continue to monitor this trend to ensure that women receive equitable coverage and participation opportunities.

In future generations, a continual push toward the achievement of gender equity in intercollegiate athletic settings will be required. As argued by Huffman et al. (2004), promotional gender equality cannot be achieved unless women receive coverage allocations that are equal to their NCAA women's participation rates. Furthermore, as the participation rates offered to women increase at the NCAA level (Title IX, 1997), the coverage allocations afforded to women on athletic department's websites must continue to grow at a comparable rate if equity is to be fully realized. When this goal is achieved, women's teams will finally be granted a fair opportunity to build their brand image in the same manner as men's teams in college athletic settings.

\section{Individual Nonrevenue Team Inequalities}

In addition to the similar sport team comparisons, data from this study also revealed individual coverage allocations for each of the teams included in the study. As illustrated in Table 2, when focusing on the coverage breakdowns, it was clear that several teams received no nonscroll multimedia coverage. From a brand equity standpoint (Ross, 2006), this finding is critical because the nonscroll multimedia is representative of the audio and video content that appears in prime locations on athletic departments' home Web pages. Thus, the results would seem to indicate that athletic departments are not interested in providing men's and women's cross-country, soccer, and tennis teams with prime-location opportunities to promote their teams on their websites.

Applying the brand equity theory, several concerns arise when considering individual team coverage inequalities identified in this study. Ultimately, when teams are not provided with equitable coverage on athletic department's home Web pages, they are missing out on opportunities to build their brand image in the minds of their consumers (Ross, 2006; Söderman \& Dolles, 2008). As previous research has illustrated, when teams such as men's tennis and women's softball are not allocated prime site coverage, it is possible that they will not receive benefits from the long-term consumer branding that results from positive media exposure (Duncan et al., 1994). Furthermore, as a result, the teams can be deprived of future financial successes that are generated by a strong brand image developed through promotional campaigns (Gladden \& Milne, 1999).

Outside of commercial benefits, the lack of coverage can also have long-term implications on the viability of nonrevenue teams. As explained by Coakley (1998), when athletic departments choose not to provide prime (nonscroll) multimedia coverage to the men's soccer and women's tennis teams, they are essentially sending the message that these teams are not important enough to receive audio or video content. When this occurs, it is likely that interest would wane, (Huffman et al., 2004), sports might be cut, and future athletes would be denied opportunities to develop the skills that are learned through sport participation (Pedersen, 2002). 


\section{Conclusions}

In future years, it will be essential to continue to examine the gender coverage being provided on intercollegiate athletic websites. As previously suggested, Title IX compliance will not be fully achieved until women are provided gender coverage allocations equal to their NCAA participation rates. For this to occur, the coverage allocations provided to similar sport teams would actually have to favor women's teams significantly to make up for the large coverage allocations currently provided to men's football teams. Thus, to understand the coverage being provided on intercollegiate athletic websites, research is needed that uncovers the breakdown of the individual sport team coverage. Ultimately, this will allow sport managers to identify where coverage inequalities exist on athletic departments' home Web pages and where corrective interventions are needed.

In addition to focusing on the gender coverage differences, future research should also consider the examination of website allocations for all nonrevenue sports. With the current emphasis on men's basketball and football, the possibility exists that men's nonrevenue sport teams will receive decreasing promotional opportunities on intercollegiate sites. Similar to the women's sport teams, this is a major concern because the men's nonrevenue sport teams could be missing out on opportunities to build interest in their product in future generations. For sports such as wrestling, this is a major consideration because many programs are being eliminated due to financial constraints. The identification of coverage inequalities could explain, at least in part, why some teams are not maximizing their consumer potential in college athletic environments.

The research in this study raises additional concerns because it focuses on "not-for-profit" media outlets in institutions with NCAA affiliations. If athletic departments in colleges and universities are not willing to provide equitable team coverage allocations on their home Web pages, they may be, at once, setting a precedent that has little to do with their educational mission and blurring an important distinction between "for-profit" and "not-for-profit" media policies. As noted, policies that discriminate against minor sports may well have an impact on the longevity of those sports and affect their availability for future generations of athletes.

\section{Limitations and Suggestions for Future Research}

A limitation of this research is related to the time frame used for the study. Because the research focused on media coverage during the 2005-06 academic year, it is difficult to generalize findings beyond this time frame. To fully understand the coverage being provided on athletic websites, researchers might consider extending the research beyond the parameters used in the current study. In particular, it would be useful to investigate intercollegiate websites over an extended time period ( 5 to 10 years) to determine whether gender coverage inequalities had improved over time. For example, researchers could focus on the advertisement and multimedia coverage being provided on Football Bowl Subdivision websites during a 5 year time frame.

The current research also focused on similar sport team coverage in selected sports. As such, it did not compare men's and women's basketball, nor did it 
include football. To provide insight into the overall gender coverage allocations, future projects should focus on the impact that high profile sport allocations have on the nonrevenue-generating teams-whether male or female.

\section{Note}

1. The emphasis of the study was to identify coverage differences between similar sport teams housed on intercollegiate athletic websites. As a result the focus was on comparing similar men's and women's sport teams (e.g., men's and women's tennis) and not on determining whether coverage inequities existed between "sex-appropriate" and "sex-inappropriate" sport events.

\section{References}

Aaker, D.A. (1996). Building strong brands. New York: The Free Press.

Bryant, J. (1980). A two-year selective investigation of the female athlete in sport as reported in the paper media. Arena Review, 4(2), 32-44.

Coakley, J.J. (1998). Sport in society: Issues and controversies. Boston: McGraw-Hill.

Cuneen, J., \& Sidwell, M.J. (1998). Gender portrayals in Sports Illustrated for Kids: Advertisements: A content analysis of prominent and supporting models. Journal of Sport Management, 12(1), 39-50.

Cunningham, G.B., \& Sagas, M. (2002). Utilizing a different perspective: Brandy equity and media coverage of intercollegiate athletics. International Sports Journal, 6, 134145.

Cunningham, G.B., Sagas, M., Satore, M.L., Amsden, M., \& Schellhase, A. (2004). Gender representation in the NCAA News: Is the glass half full or half empty? Sex Roles: A. Journal of Research, 50(11/12), 861-870.

Duncan, M.C., Messner, M.A., Williams, A., \& Jensen, K. (1994). Gender, stereotyping in television sports. In S. Birrell \& C.L. Cole (Eds.), Women, culture, and sport. Champaign, IL: Human Kinetics.

Duncan, M.C., \& Sayaovong, A. (1990). Photographic images and gender in Sports Illustrated for Kids. Play and Culture, 3, 91-116.

Fink, J., \& Kensicki, L. (2002). An imperceptible difference: Visual and textual constructions of femininity in Sports Illustrated and Sports Illustrated for Women. Mass Communication \&. Society, 5(3), 317-339.

Gladden, J.M., \& Milne, G.R. (1999). Examining the importance of brand equity in professional sport. Sport Marketing Quarterly, 8(1), 21-29.

Gladden, J.M., Milne, G.R., \& Sutton, W.A. (1998). A conceptual framework for assessing brand equity in Division I college athletics. Journal of Sport Management, 12, 1-19.

Huffman, S., Tuggle, C.A., \& Rosengard, D.S. (2004). How campus media cover sports: The gender-equity issue, one year later. Mass Communication \& Society, 7(4), 475489.

Kane, M.J. (1988). Media coverage of the female athlete before, during, and after Title IX: Sports Illustrated revisited. Journal of Sport Management, 2, 87-99.

Keller, K.L. (2003). Strategic brand management: Building, measuring, and managing brand equity, 2nd Ed. Hemel Hempstead: Prentice Hall.

Kennedy, C.L. (2007). The athletic directors' dilemma: “\$\$ \& women's sports." Gender Issues, 24, 34-45.

Malec, M.A. (1994). Gender (in)equity in the NCAA News? Journal of Sport and Social Issues, 181, 376-378.

McGregor, E. (1989). Mass media and sport: Influences on the public. Physical Educator, $46,52-55$. 
NCAA Sports Sponsorship and Participation Rates Report. (2006). The Online Resource for the National Collegiate Athletic Association (NCAA). Retrieved February 21, 2008, from: http://www.ncaa.org/library/research/participation rates/19822006/1982_2006_participation_rates.pdf

Pedersen, P.M. (2002). Investigating interscholastic equity on sports page: A content analysis of high school athletics newspaper articles. Sociology of Sport Journal, 19(4), 419-432.

Riffe, D., Lacy, S., \& Fico, F.G. (2005). Analyzing media messages: Using quantitative content analysis in research. Mahwah, NJ: Lawrence Erlbaum.

Rintala, J. \& Birrell, S. (1984). Fair treatment for the active female: A content analysis of Young Athlete magazine. Sociology of Sport Journal, 1, 231-250.

Ross, S. (2006). A conceptual framework for understanding spectator-based brand equity. Journal of Sport Management, 20, 22-38.

Sagas, M., Cunningham, G.B., Wigley, B.J., \& Ashley, F.B. (2000). Internet coverage of university softball and baseball websites: The inequity continues. Sociology of Sport Journal, 17, 198-205.

Sagas, M., Cunningham, G.B., Wigley, B.J., \& Ashley, F.B. (2004). Internet coverage of university softball and baseball websites: The inequity continues. In D. Rowe (Ed.), Critical readings: Sport, culture and the media, 340-349. Berkshire, UK: McGraw Hill.

Shifflett, B., \& Revelle, R. (1994). Equity Revisted. Journal of Sport and Social Issues, 18(4), 379-383.

Söderman, S., \& Dolles, H. (2008). Strategic fit in international sponsorship. International Journal of Sports Marketing \& Sponsorship, 9(2), 95-110.

Student-athlete participation rate reaches all-time plateau. (2006, February 13). The NCAA News, 4(4), 9.

Title IX. Educational Amendments of 1972. (Title 20 U.S.C. Sections 1681-1688). (2007). U.S. Department of Labor. Retrieved May 9, 2007, from: http://www.dol.gov/oasam/ regs/statutes/titleix.htm.

Title IX. A sea change in gender equity in education. (1997). U.S. Department of Educaton. Retrieved July 19, 2008, from: http://www.ed.gov/pubs/TitleIX/part2.html.

Wann, D.L., Schrader, M.P., Allison, J.A., \& McGeorge, K.K. (1998). The inequitable newspaper coverage of men's and women's athletics at small, medium, and large universities. Journal of Sport and Social Issues, 22(1), 79-87. 